\section{(A) Check for updates}

Cite this: Dalton Trans., 2019, 48, 15198

Received 18th July 2019,

Accepted 6th September 2019

DOI: 10.1039/c9dt02951f

rsc.li/dalton

\title{
Mechanistic insight into novel sulfoxide containing SABRE polarisation transfer catalysts $\uparrow+$
}

\author{
Ben. J. Tickner, (D) a Jennifer S. Lewis, (D) a Richard O. John, (D) a \\ Adrian C. Whitwood (iD ${ }^{b}$ and Simon B. Duckett (iD *a
}

\begin{abstract}
Signal Amplification By Reversible Exchange (SABRE) is a hyperpolarisation technique that commonly uses $\left[\mathrm{Ir}(\mathrm{H})_{2}\right.$ (carbene)(substrate) $\left.{ }_{3}\right] \mathrm{Cl}$ complexes to catalytically transfer magnetisation from para-hydrogen derived hydride ligands to coordinated substrates. Here, we explore the reactivity of a novel class of such catalysts based on sulfoxide containing $\left[\mathrm{IrCl}(\mathrm{H})_{2}(\right.$ carbene $\left.)(\mathrm{DMSO})_{2}\right]$, which are involved in the hyperpolarisation of pyruvate using SABRE. We probe the reactivity of this species by NMR and DFT and upon reaction with sodium pyruvate establish the formation of two isomers of $\left[\operatorname{Ir}(\mathrm{H})_{2}\left(\eta^{2}\right.\right.$-pyruvate)(DMSO)(IMes)]. Studies with related disodium oxalate yield $\left[\mathrm{Ir}_{2}(\mathrm{H})_{4}(\mathrm{IMes})_{2}(\mathrm{DMSO})_{2}\left(\eta^{2}-\kappa^{2}\right.\right.$-Oxalate) $]$ that is characterised by NMR and X-ray diffraction.
\end{abstract}

\section{Introduction}

Small molecule bond activation is an important area of inorganic chemistry that finds a central role in a range of applications in biochemistry, ${ }^{1}$ recycling, ${ }^{2}$ and organic synthesis. ${ }^{3}$ In fact, many rather inert reagents such as $\mathrm{CO}_{2}{ }^{4}$ and $\mathrm{R}_{3} \mathrm{CH}^{5}$ can be activated by light ${ }^{6}$ or transition metal systems. ${ }^{7,8}$ The activation of small homonuclear diatomic molecules such as $\mathrm{H}_{2}$ and $\mathrm{O}_{2}$ by oxidative addition to metal centres has been known for many years. ${ }^{9,10}$ It typically occurs via a concerted mechanism wherein the newly introduced groups are located in a cis relationship. ${ }^{11}$ Activation of more polar molecules such as $\mathrm{CH}_{3} \mathrm{I}$ is, however, more often complex and this difference is revealed in the trans relationship between the two newly introduced groups. ${ }^{9}$ Orbital overlap effects during $\mathrm{H}_{2}$ addition, as revealed through density function theory (DFT), are also complex with repulsive interactions between filled orbitals on the metal and $\mathrm{H}_{2}$ yielding a barrier to the oxidative addition process that must be overcome. ${ }^{12}$

Many catalytic processes exploit the oxidative addition of $\mathrm{H}_{2}$ to a transition metal centre by enabling the subsequent transfer of the two hydrogen atoms into an unsaturated centre ${ }^{13,14}$ However, recent examples in main group chemistry involving frustrated Lewis pairs mean that direct addition is

\footnotetext{
${ }^{a}$ Center for Hyperpolarization in Magnetic Resonance (CHyM), University of York, Heslington, York, YO10 5NY, UK. E-mail: simon.duckett@york.ac.uk

${ }^{b}$ Department of Chemistry, University of York, Heslington, York, YO10 5DD, UK $\dagger$ Dedicated to Prof. Robin N. Perutz on the occasion of his $70^{\text {th }}$ birthday. \$Electronic supplementary information (ESI) available. CCDC 1941589. For ESI and crystallographic data in CIF or other electronic format see DOI: 10.1039/ c9dt02951f
}

also possible. ${ }^{15}$ Understanding of these reactions can be improved by exploiting a technique known as para-Hydrogen Induced Polarisation (PHIP) to detect reaction intermediates. ${ }^{16,17}$ This process incorporates the two protons of a single para-hydrogen $\left(p-\mathrm{H}_{2}\right)$ molecule into a substrate via a hydrogenation reaction to see the PHIP effect. $p-\mathrm{H}_{2}$ is a spin isomer of $\mathrm{H}_{2}$ and exists as a singlet state with a nuclear spin order of zero. $\mathrm{H}_{2}$ gas can be enriched (>98\%) in its para state by simply cooling it in the presence of a paramagnetic catalyst such as $\mathrm{Fe}_{2} \mathrm{O}_{3}$ or activated charcoal. ${ }^{18-20}$ If the spin orientation of $p-\mathrm{H}_{2}$ survives the ensuing hydrogenation reaction the NMR properties of the product can be harvested to increase product detectability. This effect was exemplified in 1986 by Bowers and Weitekamp ${ }^{21,22}$ with Eisenberg and Bargon ${ }^{23,24}$ producing similar independent observations around the same time. As the net nuclear spin of $p-\mathrm{H}_{2}$ is zero it is invisible to an NMR experiment but once the symmetry of its two protons is broken the resulting spin order can be detected. In fact, the NMR signal intensity of the now NMR visible, and hyperpolarised, product is derived from the resulting large non-Boltzmann populations that lie across its nuclear spin energy levels. Since its introduction PHIP has been used to detect low concentration analytes and true intermediates in the field of catalysis. ${ }^{22,25-27}$ Excitement has resulted from the hydrogenation of some unsaturated clinical agents which has led to their in vivo MRI detection. ${ }^{28-30}$

Since 2009, the $p-\mathrm{H}_{2}$ based method Signal Amplification By Reversible Exchange (SABRE) has been used to harness signal gains from $p-\mathrm{H}_{2}$ without the need for the direct hydrogenation of a substrate (sub). ${ }^{31}$ It achieves the catalytic transfer of magnetisation into a substrate through the formation of a $J$-coupled network within the associated catalyst. ${ }^{32}$ The first 
step in SABRE typically involves the conversion of a stable 16 electron precursor such as [IrCl(COD)(IMes)] (1) (where IMes = 1,3-bis(2,4,6-trimethylphenyl)imidazol-2-ylidene and $\mathrm{COD}=$ cis,cis-1,5-cyclooctadiene) into an intermediate [Ir(COD)(IMes) (sub)]Cl which then undergoes hydrogen addition to form highly reactive $\left[\operatorname{Ir}(\mathrm{H})_{2}(\mathrm{COD})(\mathrm{IMes})(\mathrm{sub})\right] \mathrm{Cl}^{33-35}$ Subsequent hydrogenation of the COD ligand then leads to a SABRE catalyst such as $\left[\operatorname{Ir}(\mathrm{H})_{2}(\mathrm{IMes})(\mathrm{sub})_{3}\right] \mathrm{Cl}$ which importantly reversibly binds both $\mathrm{H}_{2}$ and sub. In SABRE, $\mathrm{H}_{2}$ addition to square planar $[\operatorname{Ir}(\mathrm{COD})(\mathrm{IMes})(\mathrm{Sub})] \mathrm{Cl}$ typically occurs over the COD-Ir-Sub axis rather than the COD-Ir-IMes axis. ${ }^{36}$ This observation has been explained in terms of both reduced steric interactions with the bulky carbene ligand and electronic effects in terms of orbital interactions. ${ }^{36}$ It has been suggested that $\mathrm{H}_{2}$ addition is favoured over axis containing ligands with $\pi$ acceptor orbitals which provide additional stabilising interactions as the geometry of the complex changes during the addition step. ${ }^{37}$

The most common substrate molecules used in SABRE have proven to feature $\mathrm{N}$-donor sites that readily coordinate to iridium. N-Heterocycles such as pyridine, ${ }^{31,38-41}$ nicotinamides, ${ }^{31,42,43}$ pyrazines, ${ }^{39,40}$ and pyrazoles ${ }^{41}$ reflect common examples although other $N$-functionalities found in nitriles ${ }^{44}$ and amines ${ }^{45}$ have been used. It has recently been reported that in the presence of a stabilising sulfoxide coligand, the reversible coordination and subsequent hyperpolarisation of oxygen ligating pyruvate can occur. ${ }^{46}$

The direct hyperpolarisation of pyruvate was made possible in this case by the formation of the novel polarization transfer catalyst $\left[\operatorname{Ir}(\mathrm{H})_{2}\left(\eta^{2}\right.\right.$-pyruvate)(DMSO)(IMes)]. In addition to this active catalyst, $\left[\mathrm{IrCl}(\mathrm{H})_{2}(\mathrm{DMSO})_{2}(\mathrm{IMes})\right]$, is also present in solution and is expected to be critical in improving the efficiency of this important hyperpolarisation transfer process. In this work we investigate the formation, behaviour, and ligand exchange processes exhibited by this sulfoxide containing polarisation transfer catalyst. We do this in solvents that were purchased from Sigma and used without further purification as our aim is to study reactivity without taking any special precautions. This is reflective of the most likely scenario when used by the non-specialist. We extend this method to include an examination of the behaviour of oxalate with the aim of developing the range of materials that can be hyperpolarised with sulfoxide containing SABRE polarisation transfer catalysts.

\section{Results and discussion}

\section{Formation of $\left[\operatorname{Ir}(\mathrm{COD})(\mathrm{IMes})\left(\mathrm{OH}_{2}\right)\right] \mathrm{Cl}(2)$ from $[\operatorname{IrCl}(\mathrm{COD})$ (IMes)] (1)}

When the SABRE precatalyst [ $\operatorname{IrCl}(\mathrm{COD})(\mathrm{IMes})](\mathbf{1})$ is dissolved in $0.6 \mathrm{~mL}$ of methanol- $d_{4}$ at $298 \mathrm{~K},{ }^{1} \mathrm{H}$ NMR resonances can be observed for 1 in addition to a minor product, 2 which forms at the $\sim 2 \%$ level. The ratio of this product increases to $13 \%$ after the addition of $50 \mu \mathrm{L} \mathrm{H}_{2} \mathrm{O}$, as shown in Fig. 1 thereby confirming a role of the original $\mathrm{H}_{2} \mathrm{O}$ contaminant in metha-

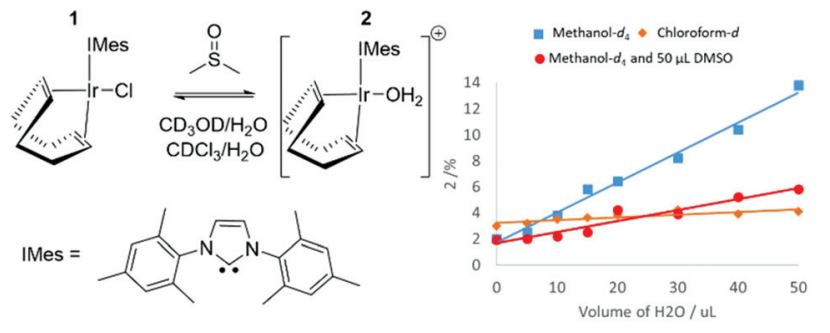

Fig. 1 Demonstrating the proportion of 2 in solution increases with the level of added water in the solvents methanol and chloroform in addition to a methanol-DMSO mixture thereby confirming its identity as [ Ir(COD)(IMes) $\left.\left(\mathrm{OH}_{2}\right)\right] \mathrm{Cl}$ as shown.

nol- $d_{4}$. When this experiment was repeated in a solution of $0.6 \mathrm{~mL}$ methanol- $d_{4}$ doped with $5 \mu \mathrm{L}$ DMSO, the ratio of 2 formed after the addition of $50 \mu \mathrm{L}$ of $\mathrm{H}_{2} \mathrm{O}$ proved to be just $6 \%$. It is noteworthy that no evidence for $[\operatorname{IrCl}(\mathrm{COD})(\mathrm{DMSO})$ (IMes)] was apparent. A similar ${ }^{1} \mathrm{H}$ NMR measurement of $\mathbf{1}$ in a solution of $\mathrm{CDCl}_{3}$ revealed the presence of 2 at the $3 \%$ level. Subsequent addition of $\mathrm{H}_{2} \mathrm{O}$ increases this to $5 \%$ but the immiscibility of $\mathrm{CDCl}_{3}$ and $\mathrm{H}_{2} \mathrm{O}$ prevents the use of high water concentrations. Hence, the equilibrium position between 1 and $\mathbf{2}$ is dependent on solvent choice and water concentration. 2 is assigned as $\left[\operatorname{Ir}(\mathrm{COD})(\mathrm{IMes})\left(\mathrm{OH}_{2}\right)\right] \mathrm{Cl}$ which is further confirmed by $2 \mathrm{D}$ NMR characterisation data (see ESI which shows a NOE between the bound aqua ligand at $\delta 8.15$ and the IMes backbone at $\delta 2.16 .{ }^{1} \mathrm{H}$ NMR resonances for hexa-aqua species are often found between $\delta 8$ and $\delta 11 .^{47}$ The formation of 2 is not unexpected as iridium aqua complexes are known and the reactions performed throughout this work are not completed under anhydrous conditions because our aim is to achieve SABRE catalysis using an air stable precursor with minimum end-user challenge. ${ }^{48-50}$

DFT calculations have been used to further confirm these product assignments, with their predicted relative energies detailed in Table 1 (see ESI $\$$ for details). These calculations used full models of the complexes, [Ir(COD)(IMes)(X)], and are relative to a zero point which includes all species (indicated complex, DMSO, $\mathrm{H}_{2} \mathrm{O}$ and $\mathrm{CH}_{3} \mathrm{OH}$ ) in an equimolar amount. They do not reflect transition state barriers and excess reagents are not accounted for. These calculations confirm that $\mathbf{1}$, where $\mathrm{X}=\mathrm{Cl}$, is most stable in agreement with experiment. $\left[\operatorname{Ir}(\mathrm{COD})(\mathrm{IMes})\left(\mathrm{OH}_{2}\right)\right] \mathrm{Cl}, 2$ is predicted to be more stable than the corresponding methanol or sulfoxide adducts, again supporting our NMR observations.

Table 1 Relative enthalpy $(H)$ and Gibbs free energies $(G)$ of a series of [Ir(COD)(IMes)(X)] complexes according to DFT calculations

\begin{tabular}{lll}
\hline $\mathrm{X}$ & $H / \mathrm{kJ} \mathrm{mol}^{-1}$ & $G / \mathrm{kJ} \mathrm{mol}^{-1}$ \\
\hline $\mathrm{Cl}$ & 0 & 0 \\
$\mathrm{OH}_{2}$ & 52.8 & 57.0 \\
$S$-DMSO & 42.3 & 68.9 \\
$\mathrm{HOCH}_{3}$ & 56.1 & 69.4
\end{tabular}




\section{Formation of $\left[\mathrm{IrCl}(\mathrm{H})_{2}(\mathrm{DMSO})_{2}(\mathrm{IMes})\right](3)$}

When $\mathrm{H}_{2}$ is added to an equilibrium mixture of $\mathbf{1}$ and 2 containing 4 equivalents of DMSO in methanol- $d_{4}$ at $245 \mathrm{~K}$ the initial ${ }^{1} \mathrm{H}$ NMR spectra reveal two hydride resonances at $\delta-15.49$ and $\delta-21.51$ which share a mutual $J$ coupling of 5.5 Hz. Low temperature NMR characterisation of the complex yielding these signals confirms it to be of the form $\left[\operatorname{Ir}(\mathrm{H})_{2}(\mathrm{IMes})(\mathrm{DMSO})_{2}(\mathrm{~L})\right], \mathbf{3 .}^{46}$ The formation of iridium(III) sulfoxide complexes bound through sulphur for use in SABRE hyperpolarisation studies has been reported previously. ${ }^{51}$ When this hydrogenation reaction is examined at $245 \mathrm{~K}$ in $\mathrm{CDCl}_{3}$ or dichloromethane- $d_{2}$ (DCM- $\left.d_{2}\right)$ hydride resonances appear at $\delta-15.50, \delta-21.12$ and $\delta-15.67, \delta-21.36$, respectively. The similarity in these signals suggests the common presence of 3 in both cases. This chemistry is complicated, however, by the fact 3 is unstable in solution over long timescales, as detailed in the ESI. +

The identity of 3 was further confirmed by repeating this experiment using [IrBr(COD)(IMes)], as the corresponding reaction product $\left[\operatorname{IrBr}(\mathrm{H})_{2}(\mathrm{DMSO})_{2}(\mathrm{IMes})\right]$ yields hydride signals at $\delta-15.67$ and $\delta-20.45$ in methanol- $d_{4}$ which are clearly different to those of 3 . Furthermore, when $\left[\operatorname{Ir}\left(\mathrm{CH}_{3} \mathrm{CN}\right)(\mathrm{COD})(\mathrm{IMes})\right] \mathrm{PF}_{6}$ is used instead, $\left[\operatorname{Ir}(\mathrm{H})_{2}\left(\mathrm{CH}_{3} \mathrm{CN}\right)\right.$ $\left.(\mathrm{DMSO})_{2}(\mathrm{IMes})\right] \mathrm{PF}_{6}$ forms which yields signals at $\delta-15.76$ and $\delta-19.83$ at $255 \mathrm{~K}$; we note there was no evidence for the displacement of $\mathrm{CH}_{3} \mathrm{CN}$ by DMSO in the associated NMR spectra. Hence, the hydride resonance in these complexes shift according to the identity of the ligand that is trans to it thereby confirming the indicated product identities. The identity of 3 was also studied by DFT as detailed in the results shown in Table 2. $\left[\operatorname{IrCl}(\mathrm{H})_{2}(\mathrm{DMSO})_{2}\right.$ (IMes)] was found to be lower in energy than the corresponding species where chloride is replaced by water, methanol or sulfoxide.

When the reaction of $\mathrm{H}_{2}$ with an equilibrium mixture of 1 and 2 in methanol- $d_{4}$ containing DMSO was monitored at $245 \mathrm{~K}$ (Fig. 2) no evidence for the formation of any $\mathrm{H}_{2}$ addition products except 3 is observed. This suggests that $\mathrm{H}_{2}$ addition is slow, and subsequent COD hydrogenation in intermediate $\mathbf{1}-\mathbf{H}_{2}$ of Fig. 2 is fast. Interestingly, the proportion of 2 remains roughly constant as this conversion proceeds thereby suggesting any equilibrations involving it are also slow. The route to 3 is therefore most likely to involve direct $\mathrm{H}_{2}$ addition to 1 rather than 2. DFT confirms that $\mathrm{H}_{2}$ addition to 1 proceeds over its COD-Ir-Cl axis rather than the COD-Ir-IMes axis according to the relative energies of the corresponding products (see ESI ). This is supported by the fact that when this $\mathrm{H}_{2}$ addition

Table 2 Relative enthalpy $(H)$ and Gibbs free energies $(G)$ of a series of $\left[\mathrm{IrX}(\mathrm{H})_{2}(\mathrm{DMSO})_{2}(\mathrm{IMes})\right]$ complexes according to DFT calculations

\begin{tabular}{lll}
\hline $\mathrm{X}$ & $H / \mathrm{kJ} \mathrm{mol}^{-1}$ & $G / \mathrm{kJ} \mathrm{mol}^{-1}$ \\
\hline $\mathrm{Cl}$ & 0 & 0 \\
$\mathrm{OH}_{2}$ & 24.4 & 34.3 \\
$S$-DMSO & 39.1 & 70.8 \\
$\mathrm{ODCH}_{3}$ & 29.3 & 45.4
\end{tabular}
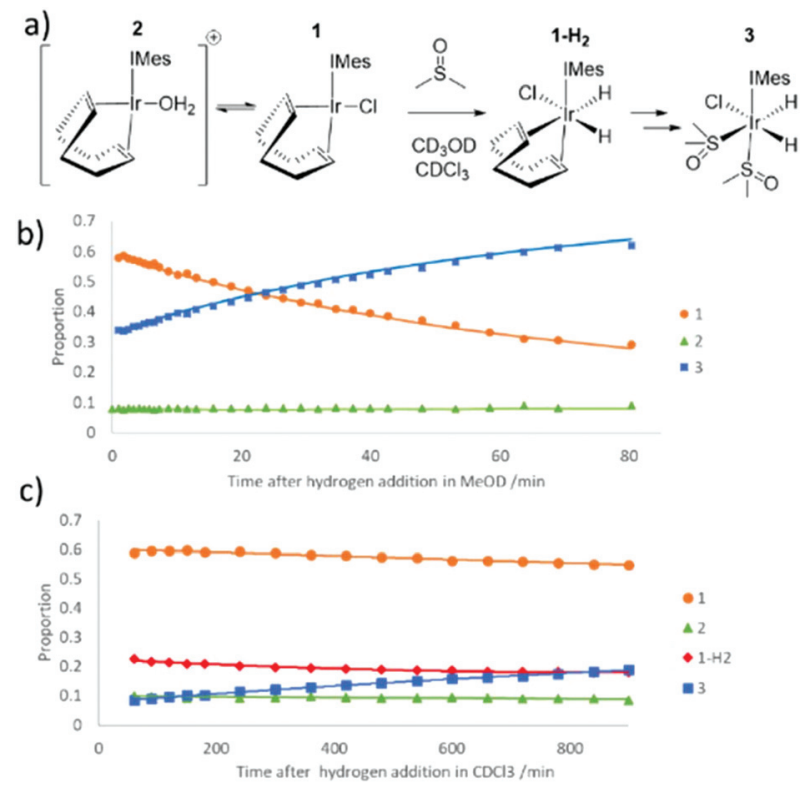

Fig. 2 (a) Reaction steps involved in the conversion of 1 to 3 in the presence of DMSO and $\mathrm{H}_{2}$, (b) time course for the reaction, as determined in methanol- $d_{4}$ solution when the starting concentrations are $5 \mathrm{mM}$ [ $\mathrm{IrCl}(\mathrm{COD})(\mathrm{IMes})], 1 \mu \mathrm{L}$ DMSO and 3 bar hydrogen pressure and (c) analogous reaction time course data in $\mathrm{CDCl}_{3}$ at $245 \mathrm{~K}$.

reaction is monitored in $\mathrm{CDCl}_{3}$ at $245 \mathrm{~K}$, resonances corresponding to $\mathbf{1}-\mathbf{H}_{2}$, at $\delta-13.39$ and $\delta-18.42$, are detected in addition to those of $\mathbf{3}$. The resonances for $\mathbf{1}-\mathbf{H}_{\mathbf{2}}$ rapidly disappear upon warming this solution to $298 \mathrm{~K}$ where 3 then forms.

\section{Ligand exchange processes of $\left[\operatorname{IrCl}(\mathrm{H})_{2}(\mathrm{DMSO})_{2}(\mathrm{IMes})\right]$ (3)}

When 3 is formed from a methanol- $d_{4}$ solution containing $2 \mathrm{mg}$ of 1, $1 \mu \mathrm{L}$ of DMSO and 3-bar $\mathrm{H}_{2}$, its hydride resonances appear very broad at $298 \mathrm{~K}$ (line width of $\sim 120 \mathrm{~Hz}$ ) which is consistent with rapid hydrogen loss. This deduction is confirmed upon shaking methanol- $d_{4}$ solutions of 3 with 3-bar $p-\mathrm{H}_{2}$ for 10 seconds at $65 \mathrm{G}$ at $298 \mathrm{~K}$. Its hydride resonances exhibit PHIP signal enhancement alongside a free DMSO signal that yields a weak SABRE ${ }^{1} \mathrm{H}$ NMR signal enhancement of 7-fold (see ESI + ). This is consistent with the reversible pairwise addition of $\mathrm{H}_{2}$ to 3 and loss of DMSO. Product 3 actually yields four distinct ${ }^{1} \mathrm{H}$ NMR signals for the methyl groups of its two DMSO ligands. The DMSO ligand cis to carbene yields a pair of inequivalent $\mathrm{CH}_{3}$ signals at $\delta 2.83$ and 3.12 while DMSO trans to carbene resonates at $\delta 3.19$ and 3.27. Upon selective excitation of bound DMSO resonances cis to carbene in 3, evidence for chemical exchange into free DMSO is observed. In contrast, we observe no exchange of the DMSO ligand that lies trans to carbene on this timescale although we do observe interchange of the inequivalent $\mathrm{CH}_{3}$ groups. This suggests that loss of the DMSO ligand cis to IMes accounts for this scrambling of the inequivalent $\mathrm{CH}_{3}$ resonances of the DMSO trans to IMes.

Measuring the change in these resonance's signal intensities as a function of time after the initial r.f. excitation step 
allowed the associated ligand loss rates to be calculated. The rate of reversible hydrogen loss, $k_{\mathrm{H}_{2}}$, was found to be $3.31 \pm$ $0.25 \mathrm{~s}^{-1}$ at $263 \mathrm{~K}$ and is faster than that seen in many related systems. ${ }^{52}$ Loss, and hence exchange of the DMSO ligand cis to IMes, was found to occur on a similar timescale with $k_{\mathrm{DMSO}}$ $3.35 \pm 0.01 \mathrm{~s}^{-1}$ at $263 \mathrm{~K}$. Repeating these measurements at different temperatures allowed the transition state barriers for these two processes to be determined as $\Delta \mathrm{H}^{ \pm}{ }_{\left(\mathrm{H}_{2}\right)} 78 \pm 6$ $\mathrm{kJ} \mathrm{mol}{ }^{-1}, \Delta \mathrm{S}^{ \pm}{ }_{\left(\mathrm{H}_{2}\right)} 60 \pm 25 \mathrm{~J} \mathrm{~K}^{-1} \mathrm{~mol}^{-1}$ and $\Delta \mathrm{H}^{ \pm}{ }_{\text {(DMSO) }} 79 \pm 6$ $\mathrm{kJ} \mathrm{mol}{ }^{-1}, \Delta \mathrm{S}^{ \pm}$(DMso) $66 \pm 8 \mathrm{~J} \mathrm{~K}^{-1} \mathrm{~mol}^{-1}$ respectively. This enthalpic barrier to hydrogen loss is comparable to those for similar complexes, overall the entropy change suggests that a dissociative pathway is adopted. ${ }^{53}$

The effects of $\mathrm{H}_{2}$ pressure and DMSO concentration on these exchange processes were also studied in methanol- $d_{4}$ at $243 \mathrm{~K}$ for differing reagent concentrations. $k_{\mathrm{H}_{2}}$ proved to increase at higher $\mathrm{H}_{2}$ concentrations before reaching a plateau as detailed in the ESI.t The rate of DMSO exchange is unaffected by increasing DMSO or $\mathrm{H}_{2}$ concentration. We therefore propose that DMSO and $\mathrm{H}_{2}$ loss proceed via formation of the common 16-electron intermediate [ $\left.\operatorname{IrCl}(\mathrm{H})_{2}(\mathrm{DMSO})(\mathrm{IMes})\right]$ in what is a dissociative first step. $\mathrm{H}_{2}$ exchange then proceeds via the formation of $\left[\mathrm{IrCl}(\mathrm{H})_{2}\left(\mathrm{H}_{2}\right)\right.$ (DMSO)(IMes)]; such indirect $\mathrm{H}_{2}$ exchange, rather than direct $\mathrm{H}_{2}$ loss, has been reported for several similar systems. ${ }^{51,54}$ When similar EXSY data were collected in $\mathrm{CD}_{2} \mathrm{Cl}_{2}$, the rate of hydrogen and DMSO loss proved to be slower than those in methanol- $d_{4}$, as summarised in Table 3.

These deductions were confirmed through further DFT calculations that revealed the products of direct $\mathrm{H}_{2}$ loss to form a 16 electron product as being highly energetically unfavourable, as shown in Table 4 . The five coordinate product formed by loss of DMSO trans to carbene proved highly unstable, undergoing spontaneous rearrangement to form an intermediate with a vacancy in the equatorial plane; this is consistent with the EXSY data. In contrast, the predicted ligand dissociation pathway involves the formation of five-coordinate $\left[\operatorname{IrCl}(\mathrm{H})_{2}(\mathrm{DMSO})(\mathrm{IMes})\right]$ via loss of the DMSO ligand that lies cis to carbene.

Even at low temperature (245-265 K), H/D exchange leading to $\left[\operatorname{IrCl}(\mathrm{D})(\mathrm{H})(\mathrm{DMSO})_{2}(\mathrm{IMes})\right] \quad(\mathbf{3}-\boldsymbol{d})$ and $[\mathrm{IrCl}$ $(\mathrm{D})_{2}(\mathrm{DMSO})_{2}$ (IMes)] was evident. Binding of solvent methanol to $\left[\operatorname{IrCl}(\mathrm{H})_{2}(\mathrm{DMSO})(\mathrm{IMes})\right]$ is an obvious route to deuterium exchange and the formation of these species alongside HD and $\mathrm{D}_{2}$ gas. While we do not directly observe methanol bound adducts, they are suggested to form in similar systems and indeed proposed to account for the hydrogen isotope exchange
Table 4 Relative enthalpy $(H)$ and Gibbs free energies $(G)$ of products arising from ligand loss of 3 according to DFT calculations. These energies are relative to those of 3 and do not reflect transition state barriers

\begin{tabular}{lll}
\hline Loss of & $H / \mathrm{kJ} \mathrm{mol}^{-1}$ & $G / \mathrm{kJ} \mathrm{mol}^{-1}$ \\
\hline $\mathrm{H}_{2}$ & 89.0 & 58.5 \\
$\mathrm{Cl}$ & 39.6 & 3.9 \\
DMSO cis carbene & 32.7 & -10.1
\end{tabular}

reaction that is often observed to run in parallel to SABRE. ${ }^{50,55}$ Experimentally, at low temperature it proved possible to reliably and selectively excite the hydride resonance of 3 or $3-\boldsymbol{d}$. The selective excitation of the hydride resonances for these two species revealed their selective chemical exchange into $\mathrm{H}_{2}$ and $\mathrm{HD}$, from 3 and $3-\boldsymbol{d}$ respectively. Therefore, $k_{\mathrm{H}_{2}}$ and $k_{\mathrm{HD}}$ can be determined as previously described. These values proved to be the same within error and hence, there is little or no kinetic isotope effect which is consistent with other reports. ${ }^{56,57}$ We note that exchange between $\mathbf{3}$ and $\mathbf{3}-\boldsymbol{d}$ is not observed in the associated EXSY data which provides confirmation that the underlying deuterium exchange processes involving methanol- $d_{4}$ are slow.

\section{Formation of $\left[\operatorname{Ir}\left(\mathrm{H}_{2}\right)_{2}\left(\eta^{2}\right.\right.$-pyruvate)(DMSO)(IMes)], (4)}

When sodium pyruvate ( 5 equivalents relative to iridium) is added to a solution of preformed 3 in methanol- $d_{4}$ at $245 \mathrm{~K}$, two new hydride ligand containing products form, which correspond to isomers $\mathbf{4 a}$ and $\mathbf{4 b}$ of $\left[\operatorname{Ir}(\mathrm{H})_{2}\left(\eta^{2}\right.\right.$-pyruvate)(DMSO) (IMes)] as detailed in Fig. 3a. Logically, a further isomer of $\mathbf{4 a}$ is possible, $\mathbf{4 c}$, in which the orientation of the pyruvate is rotated but this is not observed in solution. These products are differentiated from each other by the geometry of the coordinated pyruvate ligand and their proportion is both reaction time and temperature dependent (Fig. 3b). DFT (Table 5) is used to confirm that $\mathbf{4 a}$ exhibits the ligand geometry shown in Fig. $3 \mathbf{a}$ and that $\mathbf{4 b}$ is the most stable species. Despite observation of a $10 \mathrm{~Hz}$ coupling between the pyruvate $\mathrm{COOH}$ group and the hydride trans to oxygen, according to DFT the pyruvate $\mathrm{CH}_{3}$ and DMSO groups of $\mathbf{4 a}$ are arranged in a cis fashion as shown in Fig. 3a. This deduction was further confirmed by the observation of an NOE peak between the pyruvate $\mathrm{CH}_{3}$ group and the phenyl protons on the mesityl group of the carbene ligand.

When this solution was examined with a 32 scan ${ }^{1} \mathrm{H}$ NMR measurement at $298 \mathrm{~K}$, unlike the $245 \mathrm{~K}$ data of Fig. $3 \mathrm{~b}$, the main hydride containing complex observed is $\mathbf{4 b}$ and reso-

Table 3 Rate and thermodynamic parameters for hydrogen and DMSO exchange of 3

\begin{tabular}{lllll}
\hline Solvent & Process & $k_{(263 \mathrm{~K})} / \mathrm{s}^{-1}$ & $\Delta H^{\neq} / \mathrm{kJ} \mathrm{mol}^{-1}$ & $\Delta S^{\neq} / \mathrm{J} \mathrm{K}^{-1} \mathrm{~mol}^{-1}$ \\
\hline Methanol- $d_{4}$ & Hydrogen exchange $\left(k_{\mathrm{H}_{2}}\right)$ & $3.31 \pm 0.25$ & $78 \pm 6$ & $60 \pm 25$ \\
& DMSO exchange $\left(k_{\mathrm{DMSO}}\right)$ & $3.35 \pm 0.04$ & $79 \pm 6$ & $66 \pm 8$ \\
Dichloromethane- $d_{2}$ & Hydrogen exchange $\left(k_{\mathrm{H}_{2}}\right)$ & $1.16 \pm 0.04$ & $83 \pm 8$ & $73 \pm 29$ \\
& DMSO exchange $\left(k_{\mathrm{DMSO}}\right)$ & $1.56 \pm 0.01$ & $84 \pm 2$ & $78 \pm 8$
\end{tabular}


a)
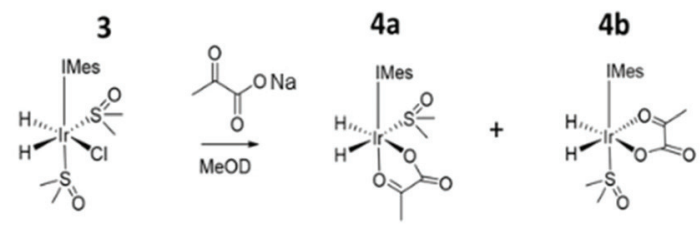

b)

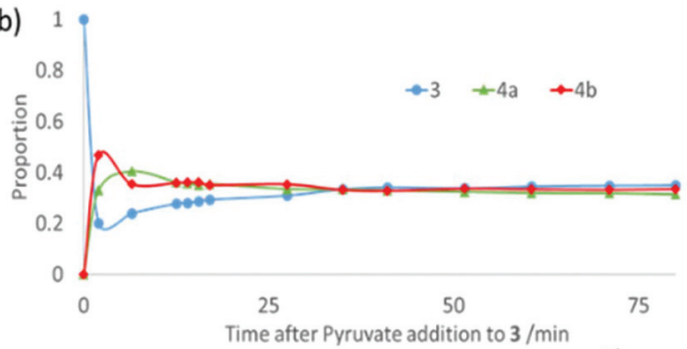

c)

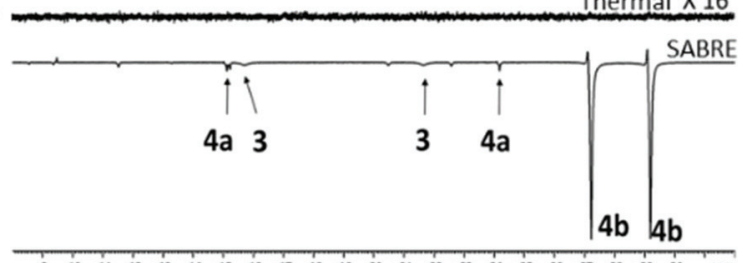

d)

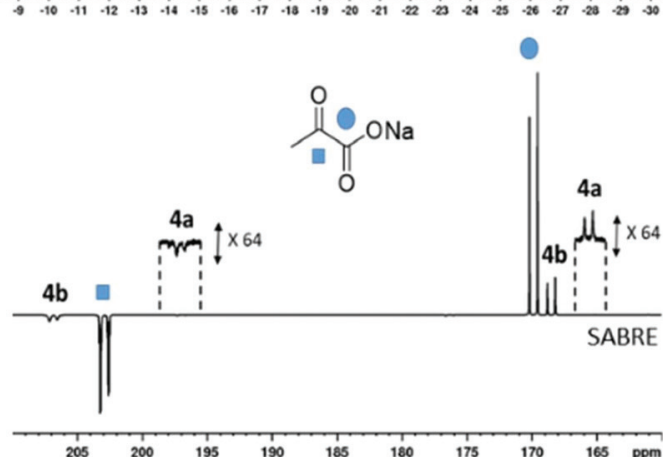

Fig. 3 (a) Reaction of 3 and pyruvate to form 4 (b) monitoring pyruvate addition to 3 using ${ }^{1} \mathrm{H}$ NMR spectroscopy. Pyruvate addition was made at room temperature to a solution of preformed 3 at $245 \mathrm{~K}$ before it was introduced into the spectrometer whose probe was at $245 \mathrm{~K}$. There is therefore a rapid temperature change at the start of this data series. Upon shaking a solution of 3 and 4 with 3 -bar $p-\mathrm{H}_{2}$ for 10 seconds at (c) $65 \mathrm{G}$ or (d) in a mu metal shield strongly hyperpolarised ${ }^{1} \mathrm{H}$ (c) or ${ }^{13} \mathrm{C}$ (d) resonances of $4 \mathrm{~b}$ are observed compared to the thermal trace.

Table 5 Relative enthalpy $(H)$ and Gibbs free energies $(G)$ of 4 according to DFT calculation

\begin{tabular}{lll}
\hline Complex & $H / \mathrm{kJ} \mathrm{mol}^{-1}$ & $G / \mathrm{kJ} \mathrm{mol}^{-1}$ \\
\hline $\mathbf{4 a}$ & 8.5 & 14.8 \\
$\mathbf{4 b}$ & 0 & 0 \\
$\mathbf{4 c}$ & 22.6 & 28.1
\end{tabular}

nances for $\mathbf{3}$ and $\mathbf{4 a}$ cannot be discerned. $\mathbf{4 a}$ and $\mathbf{4 b}$ have previously been implicated in pyruvate polarisation using SABRE and their NMR characterisation data has been reported. ${ }^{46} 4$ is also detected immediately after $\mathrm{H}_{2}$ addition to a solution of $\mathbf{1}$ containing pyruvate (5 equivalents relative to iridium) and DMSO (10 equivalents) at $298 \mathrm{~K}$. When an equilibrium mixture of 3 and 4 is shaken with 3 bar $p-\mathrm{H}_{2}$ at $65 \mathrm{G}$ enhanced hydride resonances are observed in the ${ }^{1} \mathrm{H}$ NMR spectrum as shown in Fig. 3c, which are strongest for $\mathbf{4} \mathbf{b}$.

If sodium-1,2-pyruvate- $\left[{ }^{13} \mathrm{C}_{2}\right]$ is used as the substrate and the $p-\mathrm{H}_{2}$ shaking process is performed under SABRE-SHEATH conditions in a mu metal shield (see Experimental) an enhanced ${ }^{13} \mathrm{C}$ response for the free material at $\delta 169$ and $\delta 203$ can also be readily detected. ${ }^{46}$ Two enhanced signals can be also seen for the bound pyruvate ligand in $\mathbf{4 b}$ at $\delta 168$ and $\delta 207$ in these NMR spectra. It is also possible to observe extremely weak hyperpolarised signals for the bound pyruvate ligand in 4a at $\delta 161$ and $\delta$ 198, as shown in Fig. 4d. Interestingly, when EXSY measurements are used to probe these signals, the selective excitation of the hydride resonances of $4 \mathbf{b}$ reveals no exchange into $\mathrm{H}_{2}$ on the NMR timescale. Furthermore, when ${ }^{13} \mathrm{C}$-EXSY is used to probe the bound signals of $\mathbf{4} \mathbf{b}$, no exchange is seen into free pyruvate on this timescale. Hence $\mathbf{4 b}$ appears to be relatively stable in agreement with the DFT study, but this is not consistent with the strong hydride polarisation that is evident for $\mathbf{4 b}$ in Fig. 3. Consequently, a role for 3 which is present and undergoes rapid $\mathrm{H}_{2}$ exchange as discussed earlier in its formation is indicated. It is by this route that the delivery of fresh $p-\mathrm{H}_{2}$ into 4 and the resulting enhancement of hydride and pyruvate ligand signals is achieved. As the NMR relaxation times of the ${ }^{13} \mathrm{C}$ resonances in pyruvate are much longer than those of ${ }^{1} \mathrm{H}$, slow exchange is still commensurate with the build-up of pyruvate polarisation in solution. Related relayed $p-\mathrm{H}_{2}$ enhancement effects have been described recently. ${ }^{58,59}$

An equilibrium mixture containing 4 can also be formed if sodium-1,2-pyruvate- $\left[{ }^{13} \mathrm{C}_{2}\right]$ is added to a preformed methanol- $d_{4}$ solution of $\left[\operatorname{IrBr}(\mathrm{H})_{2}(\mathrm{DMSO})_{2}(\mathrm{IMes})\right]$ (3-Br) or $\left[\operatorname{Ir}(\mathrm{H})_{2}\left(\mathrm{CH}_{3} \mathrm{CN}\right)(\mathrm{DMSO})_{2}(\mathrm{IMes})\right] \mathrm{PF}_{6}$ (3-Acn). When these samples are shaken with $p-\mathrm{H}_{2}$ for 10 seconds at $65 \mathrm{G}$ strongly hyperpolarised hydride resonances can again be observed for $\mathbf{4 b}$ in the corresponding high field NMR measurement. These resonances appear with significantly lower intensity than those achieved with 3 derived systems (35\% and 31\% of this signal

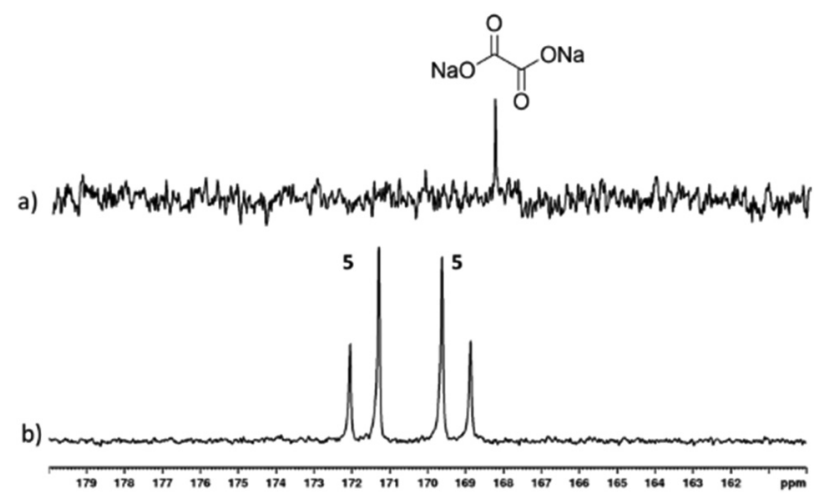

Fig. 4 (a) 128 scan ${ }^{13} \mathrm{C}$ spectrum of a solution of 1 , DMSO and sodium1,2-oxalate- $\left[{ }^{13} C_{2}\right](1: 5: 5)$ in methanol- $d_{4}$ (b) ${ }^{13} \mathrm{C}$ NMR signals seen after shaking an NMR tube with 3-bar $p-\mathrm{H}_{2}$ in a mu metal shield for 30 seconds. 
intensity respectively). Furthermore, when the $p-\mathrm{H}_{2}$ shaking step is repeated in a mu metal shield, hyperpolarised resonances for ${ }^{13} \mathrm{C}$-pyruvate are again visible. The corresponding ${ }^{13} \mathrm{C}$-pyruvate signal enhancements are typically 580 -fold and 120-fold for the 3-Br and 3-Acn derived systems respectively. These are lower than those achieved for the analogous 3 system (1070-fold) which is consistent with the reduced amount of $\mathbf{4 b}$ which is present at equilibrium when these precursors are used (22 and $23 \%$ respectively when compared to $92 \%$ with 3 ).

We note that the linewidths of the hydride resonances of $\mathbf{4 b}$ at $298 \mathrm{~K}$ are similar in each of these samples $(43-45 \mathrm{~Hz})$. Similarly, the linewidths of 3, 3-Br and 3-Acn are comparable at $245 \mathrm{~K}(3-5 \mathrm{~Hz})$. Therefore, we do not expect that differences in hydride polarisation levels seen for $\mathbf{4 b}$ in these solutions are due to different hydrogen exchange rates in $\mathbf{3}$, but rather the different binding strengths of the coligands that must be displaced by pyruvate to form 4 from 3 . Hence, whilst there appears to be a link between pyruvate polarisation level and $\mathbf{4 b}$ concentration, the identity of $\mathrm{L}$ in $\left[\operatorname{Ir}(\mathrm{H})_{2}(\mathrm{DMSO})_{2}(\mathrm{IMes}) \mathrm{L}\right]$ must play a large effect on the level of pyruvate signal enhancement. These data further confirm that $\mathbf{3}$ is important in mediating efficient $\mathrm{H}_{2}$ exchange within the $\mathbf{3} / \mathbf{4}$ hyperpolarisation mixture.

\section{Using $\left[\operatorname{IrCl}(\mathrm{H})_{2}(\mathrm{DMSO})_{2}(\mathrm{IMes})\right]$ (3) to hyperpolarise sodium- 1,2-oxalate-[ $\left[{ }^{13} \mathrm{C}_{2}\right]$}

We have shown how 3 can be formed in situ and subsequently used as a precursor to form $\left[\operatorname{Ir}(\mathrm{H})_{2}\left(\eta^{2}\right.\right.$-pyruvate)(DMSO)(IMes)], (4) which delivers SABRE enhancement to pyruvate. This $\alpha$-keto acid motif also features in oxalate, a metabolic product that binds mineral ions in the body and is found in many foods. ${ }^{60}$ Indeed, Levitt and coworkers have reported the creation of a long lived hyperpolarised ${ }^{13} \mathrm{C}_{2}$ singlet spin pair for a deuterated ester derivative of oxalate using DNP. ${ }^{61}$ Consequently, we now describe tests on sodium-1,2-oxalate$\left[{ }^{13} \mathrm{C}_{2}\right]$. This involved shaking a mixture of $\mathbf{1}$, DMSO, and sodium-1,2-oxalate- $\left[{ }^{13} \mathrm{C}_{2}\right](1: 5: 5)$ with 3-bar $p-\mathrm{H}_{2}$ in $0.6 \mathrm{~mL}$ methanol- $d_{4}$ for 30 seconds in a mu metal shield. Hyperpolarised ${ }^{13} \mathrm{C}$ resonances were observed at $\delta 169.20$ and $\delta 171.66$ that share a $J_{\mathrm{CC}}$ coupling of $76 \mathrm{~Hz}$, as shown in Fig. 4 . These signals cannot be due to free sodium-1,2-oxalate- $\left[{ }^{13} \mathrm{C}_{2}\right]$ as a single resonance is expected.

While the complexation dynamics of oxalate are complex, ${ }^{62-64}$ based on the pyruvate observations described earlier it should be possible to form a species such as $\left[\operatorname{Ir}(\mathrm{H})_{2}\left(\eta^{2}\right.\right.$-oxalate)(DMSO)(IMes)], $\mathbf{5}$ which would account for this observation. In fact, the ${ }^{13} \mathrm{C}_{2}$ NMR signal profile shown in Fig. 4 is indicative of Zeeman magnetisation in such a product rather than singlet spin order. This indicates that while ${ }^{13} \mathrm{C}$ polarisation transfer from a set of $p-\mathrm{H}_{2}$ derived hydride ligands initially results this must be associated with a $\left[\mathrm{AA}^{\prime} \mathrm{BB}^{\prime}\right]$ spin system, which converts to the [AMSX] type with inequivalent hydride ligands in high field. A product with ligand arrangement analogous to $\mathbf{4 a}$ would match with this hypothesis. ${ }^{46}$ Unfortunately, examination of the hydride region of the result- ing ${ }^{1} \mathrm{H}$ NMR spectra reveal signals for 3 at $\delta-15.45$ and $\delta$ -21.53 alongside over seven minor hydride containing complexes. None of the hydride resonances of these species correlated to these two ${ }^{13} \mathrm{C}$ signals in an overnight $2 \mathrm{D}$ measurement at $243 \mathrm{~K}$. Studying this reaction again at $315 \mathrm{~K}$, proved to be of no benefit as conversion of 3 into the same range of hydride containing species results.

In contrast, when this experiment was repeated in DCM- $d_{2}$ the hydride resonances of 3 are again observed at $\delta-15.71$ and $\delta-21.27$ but no ${ }^{13} \mathrm{C}$ oxalate derived polarisation is seen. There is very low solubility of sodium oxalate in this medium. As a consequence, samples of 3 in $\mathrm{CD}_{2} \mathrm{Cl}_{2}$ or $\mathrm{CH}_{3} \mathrm{OD}$ were prepared and reacted with $50 \mu \mathrm{L} \mathrm{D}_{2} \mathrm{O}$ solutions of sodium-1,2-oxalate$\left[{ }^{13} \mathrm{C}_{2}\right]$. Now a new product forms cleanly, that yields a hydride signal at $\delta-27.1$ alongside diagnostic resonances for the IMes at $\delta 2.10, \delta 2.34, \delta 6.99, \delta 7.15$ and DMSO at $\delta 2.92$ whose relative signal intensities suggest the presence of a $\left[\operatorname{Ir}(\mathrm{H})_{2}(\mathrm{IMes})\right.$ (DMSO) $\left.(\mathrm{L})_{n}\right]_{x}$ species, 6. Upon shaking with $p-\mathrm{H}_{2}$ the hydride resonances for 6 do not enhance, however, the addition of $3 \mathrm{~mL}$ of degassed hexane results in the growth of single crystals. Subsequent X-ray diffraction studies confirmed that the product 6 corresponds to the dimer $\left[\operatorname{Ir}_{2}(\mathrm{H})_{4}(\mathrm{IMes})_{2}(\mathrm{DMSO})_{2}\left(\eta^{2}\right.\right.$ $\kappa^{2}$-Oxalate)] with structure shown in Fig. 5 (full X-ray and NMR characterisation data are given in the in the ESI ). The ability of oxalate to form such dimers restricts its dissociation and thereby limits its use in these hyperpolarisation studies. Nonetheless, the structure of 6 reflects a common binding mode of oxalate with transition metals. ${ }^{63,65,66}$

\section{Experimental}

All NMR measurements were carried out on a $400 \mathrm{MHz}$ Bruker Avance III spectrometer using solutions at room temperature $(298 \mathrm{~K})$ unless otherwise stated. Para-hydrogen $\left(p-\mathrm{H}_{2}\right)$ was produced by passing hydrogen gas over a spin-exchange catalyst $\left(\mathrm{Fe}_{2} \mathrm{O}_{3}\right)$ and used for all hyperpolarisation experiments. This method produces constant $p-\mathrm{H}_{2}$ with ca. $93 \%$ purity. ${ }^{1} \mathrm{H}$ $(400 \mathrm{MHz})$ and ${ }^{13} \mathrm{C}(100.6 \mathrm{MHz})$ NMR spectra were recorded

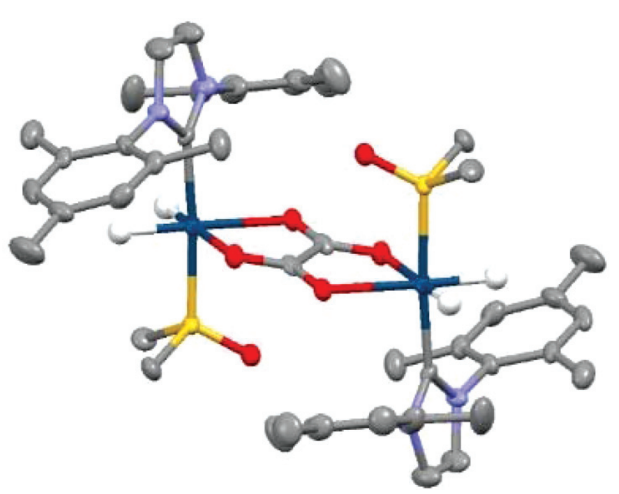

Fig. 5 Structure of $\left[\operatorname{lr}_{2}(\mathrm{H})_{4}(\mathrm{IMes})_{2}(\mathrm{DMSO})_{2}\left(\eta^{2}-\kappa^{2}\right.\right.$-Oxalate $\left.)\right]$, 6, determined by $\mathrm{X}$-ray crystallography. All non-hydride hydrogen atoms and solvent of crystallisation have been omitted for clarity. 
with an internal deuterium lock. Chemical shifts are quoted as parts per million and referenced to the solvent. ${ }^{13} \mathrm{C}$ NMR spectra were recorded with broadband proton decoupling. Coupling constants $(J)$ are quoted in Hertz.

Samples were prepared containing $2 \mathrm{mg}$ [IrCl(COD)(IMes)] precatalyst (where IMes $=1,3$-bis(2,4,6-trimethyl-phenyl)imidazole-2-ylidene and COD = cis,cis-1,5-cyclooctadiene) in $0.6 \mathrm{~mL}$ of deuterated methanol- $d_{4}$ unless otherwise stated in a $5 \mathrm{~mm}$ NMR tube that was fitted with a J. Young's tap. All commercial compounds were purchased from Sigma-Aldrich, Fluorochem, or Alfa-Aesar and used as supplied. [IrCl(COD)(IMes)] was synthesized according to a literature procedure. ${ }^{67}$ The resulting solutions were degassed by two freeze-pump-thaw cycles before the addition of 3-bar $\mathrm{H}_{2}$.

The shake and drop method was employed for recording hyperpolarised NMR spectra. This involves filling NMR tubes with $p-\mathrm{H}_{2}$ at 3 bar pressure and shaking them vigorously for 10 seconds in a $65 \mathrm{G}$ magnetic field if ${ }^{1} \mathrm{H}$ NMR spectra are to be recorded at 9.4 T. A mu metal shield is used if ${ }^{13} \mathrm{C}$ NMR spectra are to be recorded. Unless otherwise stated multiple shake and drop measurements are undertaken and average signal enhancement values quoted. Signal enhancements and exchanges rates were calculated according to literature procedures. ${ }^{68}$

\section{Conclusions}

In conclusion, we have confirmed that the complex [IrCl $(\mathrm{H})_{2}(\text { DMSO })_{2}$ (IMes)] can be used as a polarisation transfer catalyst for hyperpolarising pyruvate. Complexes of this type undergo rapid hydrogen exchange which through a mechanistic investigation involving EXSY and DFT is expected to proceed dissociatively via five coordinate $\left[\operatorname{IrCl}(\mathrm{H})_{2}(\mathrm{DMSO})\right.$ (IMes)]. When this process is completed in the presence of an $\alpha$-ketoacid, such as pyruvate, reaction to form $\left[\operatorname{Ir}(H)_{2}\left(\eta^{2}\right.\right.$-pyruvate)(DMSO)(IMes)], which exists in two coordination isomers, occurs readily. Isomer $\mathbf{4 b}$, in which the hydride ligands lie trans to pyruvate, is implicated in strong SABRE hyperpolarisation despite it undergoing slow ligand exchange. Consequently, a role for $\left[\operatorname{IrCl}(\mathrm{H})_{2}(\mathrm{DMSO})_{2}(\mathrm{IMes})\right]$, which undergoes rapid $\mathrm{H}_{2}$ and DMSO loss, is indicated in this process. When pyruvate is replaced by oxalate, stronger and more complex ligand binding is evident. The trapping of oxalate within the dimer $\mathbf{6}$ is expected to explain its much less efficient hyperpolarisation. Nonetheless, we predict that variations of the sulfoxide and NHC will enable future hyperpolarisation of oxalate and those of a wider range of other $\alpha$-keto acids.

\section{Conflicts of interest}

B. J. T. and S. B. D. (and others) are inventors on a patent application filed by the University of York related to this work (patent no. GB1818171.9, filed 7 November 2018).

\section{Acknowledgements}

We thank Dr Peter Rayner, Hannah Kettle, and Dr Victoria Annis for synthesis of the [ $\operatorname{IrCl}(\mathrm{COD})(\mathrm{IMes})],[\operatorname{IrBr}(\mathrm{COD})(\mathrm{IMes})]$ and $\left[\mathrm{Ir}\left(\mathrm{CH}_{3} \mathrm{CN}\right)(\mathrm{COD})(\mathrm{IMes})\right] \mathrm{PF}_{6}$ precatalysts. Dr Wissam Iali is thanked for early stage discussions. Financial support from the Wellcome Trust (Grants 092506 and 098335), the MRC (MR/M008991/1) and the EPSRC (B. J. T. studentship and Impact Accelerator Award G0025101) is gratefully acknowledged.

\section{References}

1 T. S. Leyh, Crit. Rev. Biochem. Mol. Biol., 1993, 28, 515542.

2 X. Liu, L. He, Y.-M. Liu and Y. Cao, Acc. Chem. Res., 2013, 47, 793-804.

3 H. Amii and K. Uneyama, Chem. Rev., 2009, 109, 21192183.

4 D. M. Ermert and L. J. Murray, Dalton Trans., 2016, 45, 14499-14507.

5 R. Pretorius, M. R. Fructos, H. Müller-Bunz, R. A. Gossage, P. J. Pérez and M. Albrecht, Dalton Trans., 2016, 45, 1459114602.

6 H. Huo, X. Shen, C. Wang, L. Zhang, P. Röse, L.-A. Chen, K. Harms, M. Marsch, G. Hilt and E. Meggers, Nature, 2014, 515, 100.

7 L.-S. Wang, R. McDonald and M. Cowie, Inorg. Chem., 1994, 33, 3735-3744.

8 M. Álvarez, E. Álvarez, M. R. Fructos, J. Urbano and P. J. Pérez, Dalton Trans., 2016, 45, 14628-14633.

9 P. B. Chock and J. Halpern, J. Am. Chem. Soc., 1966, 88, 3511-3514.

10 W. H. Thompson and C. T. Sears, Inorg. Chem., 1977, 16, 769-774.

11 K. Searles, M. Pink, K. G. Caulton and D. J. Mindiola, Dalton Trans., 2012, 41, 9619-9622.

12 C. E. Johnson and R. Eisenberg, J. Am. Chem. Soc., 1985, 107, 3148-3160.

13 N. Wang, M. Wang, Y. Wang, D. Zheng, H. Han, M. r. S. G. Ahlquist and L. Sun, J. Am. Chem. Soc., 2013, 135, 13688-13691.

14 C. R. Landis and T. W. Brauch, Inorg. Chim. Acta, 1998, 270, 285-297.

15 S. Grimme, H. Kruse, L. Goerigk and G. Erker, Angew. Chem., Int. Ed., 2010, 49, 1402-1405.

16 K. Sorochkina, V. V. Zhivonitko, K. Chernichenko, V.-V. Telkki, T. Repo and I. V. Koptyug, J. Phys. Chem. Lett., 2018, 9, 903-907.

17 V. V. Zhivonitko, K. Sorochkina, K. Chernichenko, B. Kótai, T. Földes, I. Pápai, V.-V. Telkki, T. Repo and I. Koptyug, Phys. Chem. Chem. Phys., 2016, 18, 2778427795.

18 S. Wagner, Magn. Reson. Mater. Phys., Biol. Med., 2014, 27, 195-199. 
19 D. Canet, C. Aroulanda, P. Mutzenhardt, S. Aime, R. Gobetto and F. Reineri, Concepts Magn. Reson., Part A, 2006, 28, 321-330.

20 P. M. Richardson, R. O. John, A. J. Parrott, P. J. Rayner, W. Iali, A. Nordon, M. E. Halse and S. B. Duckett, Phys. Chem. Chem. Phys., 2018, 20, 26362-26371.

21 C. R. Bowers and D. P. Weitekamp, Phys. Rev. Lett., 1986, $57,2645$.

22 C. R. Bowers and D. P. Weitekamp, J. Am. Chem. Soc., 1987, 109, 5541-5542.

23 T. C. Eisenschmid, R. U. Kirss, P. P. Deutsch, S. I. Hommeltoft, R. Eisenberg, J. Bargon, R. G. Lawler and A. L. Balch, J. Am. Chem. Soc., 1987, 109, 8089-8091.

24 R. Eisenberg, Acc. Chem. Res., 1991, 24, 110-116.

25 T. C. Eisenschmid, R. U. Kirss, P. P. Deutsch, S. I. Hommeltoft, R. Eisenberg, J. Bargon, R. G. Lawler and A. L. Balch, J. Am. Chem. Soc., 1987, 109, 8089-8091.

26 S. B. Duckett, C. L. Newell and R. Eisenberg, J. Am. Chem. Soc., 1994, 116, 10548-10556.

27 K. V. Kovtunov, I. E. Beck, V. I. Bukhtiyarov and I. V. Koptyug, Angew. Chem., Int. Ed., 2008, 47, 1492-1495.

28 P. Bhattacharya, E. Y. Chekmenev, W. H. Perman, K. C. Harris, A. P. Lin, V. A. Norton, C. T. Tan, B. D. Ross and D. P. Weitekamp, J. Magn. Reson., 2007, 186, 150-155.

29 N. M. Zacharias, H. R. Chan, N. Sailasuta, B. D. Ross and P. Bhattacharya, J. Am. Chem. Soc., 2011, 134, 934-943.

30 F. Reineri, T. Boi and S. Aime, Nat. Commun., 2015, 6, 5858.

31 R. W. Adams, J. A. Aguilar, K. D. Atkinson, M. J. Cowley, P. I. Elliott, S. B. Duckett, G. G. Green, I. G. Khazal, J. López-Serrano and D. C. Williamson, Science, 2009, 323, 1708-1711.

32 R. W. Adams, S. B. Duckett, R. A. Green, D. C. Williamson and G. G. Green, J. Chem. Phys., 2009, 131, 194505.

33 A. J. Ruddlesden, R. E. Mewis, G. G. Green, A. C. Whitwood and S. B. Duckett, Organometallics, 2015, 34, 2997-3006.

34 A. J. Ruddlesden and S. B. Duckett, Chem. Commun., 2016, 52, 8467-8470.

35 L. S. Lloyd, A. Asghar, M. J. Burns, A. Charlton, S. Coombes, M. J. Cowley, G. J. Dear, S. B. Duckett, G. R. Genov and G. G. R. Green, Catal. Sci. Technol., 2014, 4, 3544-3554.

36 K. M. Appleby, R. E. Mewis, A. M. Olaru, G. G. R. Green, I. J. S. Fairlamb and S. B. Duckett, Chem. Sci., 2015, 6, 3981-3993.

37 A. L. Sargent and M. B. Hall, Inorg. Chem., 1992, 31, 317321.

38 M. Fekete, O. Bayfield, S. B. Duckett, S. Hart, R. E. Mewis, N. Pridmore, P. J. Rayner and A. Whitwood, Inorg. Chem., 2013, 52, 13453-13461.

39 M. J. Cowley, R. W. Adams, K. D. Atkinson, M. C. Cockett, S. B. Duckett, G. G. Green, J. A. Lohman, R. Kerssebaum, D. Kilgour and R. E. Mewis, J. Am. Chem. Soc., 2011, 133, 6134-6137.

40 H. Zeng, J. Xu, J. Gillen, M. T. McMahon, D. Artemov, J.-M. Tyburn, J. A. Lohman, R. E. Mewis, K. D. Atkinson and G. G. Green, J. Magn. Reson., 2013, 237, 73-78.
41 E. B. Dücker, L. T. Kuhn, K. Münnemann and C. Griesinger, J. Magn. Reson., 2012, 214, 159-165.

42 M. L. Truong, T. Theis, A. M. Coffey, R. V. Shchepin, K. W. Waddell, F. Shi, B. M. Goodson, W. S. Warren and E. Y. Chekmenev, J. Phys. Chem. C, 2015, 119, 8786-8797.

43 P. Spannring, I. Reile, M. Emondts, P. P. Schleker, N. K. Hermkens, N. G. van der Zwaluw, B. J. van Weerdenburg, P. Tinnemans, M. Tessari and B. Blümich, Chem. - Eur. J., 2016, 22, 9277-9282.

44 R. E. Mewis, R. A. Green, M. C. Cockett, M. J. Cowley, S. B. Duckett, G. G. Green, R. O. John, P. J. Rayner and D. C. Williamson, J. Phys. Chem. B, 2015, 119, 1416-1424.

45 W. Iali, P. J. Rayner, A. Alshehri, A. J. Holmes, A. J. Ruddlesden and S. B. Duckett, Chem. Sci., 2018, 9, 3677-3684.

46 W. Iali, S. S. Roy, B. J. Tickner, F. Ahwal, A. J. Kennerley and S. B. Duckett, Angew. Chem., 2019, 131, 10377-10381.

47 A. F. Oliveri, L. A. Wills, C. R. Hazlett, M. E. Carnes, I.-Y. Chang, P. H.-Y. Cheong and D. W. Johnson, Chem. Sci., 2015, 6, 4071-4085.

48 L. Dadci, H. Elias, U. Frey, A. Hoernig, U. Koelle, A. E. Merbach, H. Paulus and J. S. Schneider, Inorg. Chem., 1995, 34, 306-315.

49 S. Ogo, N. Makihara, Y. Kaneko and Y. Watanabe, Organometallics, 2001, 20, 4903-4910.

50 S. Knecht, S. Hadjiali, D. A. Barskiy, A. Pines, G. Sauer, A. S. Kiryutin, K. L. Ivanov, A. V. Yurkovskaya and G. Buntkowsky, J. Phys. Chem. C, 2019, 123, 16288-16293.

51 B. J. Tickner, R. O. John, S. S. Roy, S. J. Hart, A. C. Whitwood and S. B. Duckett, Chem. Sci., 2019, 10, 5235-5245.

52 A. M. Olaru, A. Burt, P. J. Rayner, S. J. Hart, A. C. Whitwood, G. G. Green and S. B. Duckett, Chem. Commun., 2016, 52, 14482-14485.

53 B. J. Tickner, W. Iali, S. S. Roy, A. C. Whitwood and S. B. Duckett, ChemPhysChem, 2019, 20, 241-245.

54 B. E. Hauger, D. Gusev and K. G. Caulton, J. Am. Chem. Soc., 1994, 116, 208-214.

55 O. Semenova, P. M. Richardson, A. J. Parrott, A. Nordon, M. E. Halse and S. B. Duckett, Anal. Chem., 2019, 91, 66956701.

56 P. Zhou, A. A. Vitale, J. San Filippo Jr. and W. H. Saunders Jr., J. Am. Chem. Soc., 1985, 107, 8049-8054.

57 F. Abu-Hasanayn, A. S. Goldman and K. Krogh-Jespersen, J. Phys. Chem., 1993, 97, 5890-5896.

58 B. J. Tickner, R. O. John, S. S. Roy, S. Hart, A. C. Whitwood and S. B. Duckett, Chem. Sci., 2019, 10, 5235-5245.

59 S. S. Roy, K. M. Appleby, E. J. Fear and S. B. Duckett, J. Phys. Chem. Lett., 2018, 9, 1112-1117.

60 H. Sidhu, R. Gupta, S. K. Thind and R. Nath, Ann. Nutr. Metab., 1987, 31, 354-361.

61 C. Laustsen, G. Pileio, M. C. D. Tayler, L. J. Brown, R. C. D. Brown, M. H. Levitt and J. H. Ardenkjaer-Larsen, Magn. Reson. Med., 2012, 68, 1262-1265.

62 N. Hao, E. Shen, Y. G. Li, E. B. Wang, C. W. Hu and L. Xu, Eur. J. Inorg. Chem., 2004, 2004, 4102-4107. 
63 B. Modec, J. V. Brenčič and J. Koller, Eur. J. Inorg. Chem., 2004, 2004, 1611-1620.

64 M. Gruselle, C. Train, K. Boubekeur, P. Gredin and N. Ovanesyan, Coord. Chem. Rev., 2006, 250, 2491-2500.

65 B. Modec, J. V. Brenčič, D. Dolenc and J. Zubieta, Dalton Trans., 2002, 4582-4586.
66 M. E. Robinson, J. E. Mizzi, R. J. Staples and R. L. LaDuca, Cryst. Growth Des., 2015, 15, 2260-2271.

67 L. D. Vazquez-Serrano, B. T. Owens and J. M. Buriak, Inorg. Chim. Acta, 2006, 359, 2786-2797.

68 B. J. Tickner, W. Iali, S. S. Roy, A. C. Whitwood and S. B. Duckett, ChemPhysChem, 2019, 20, 241-245. 